\title{
Left atrial appendage anatomy and function: short term response to sustained atrial fibrillation
}

\author{
M J Weigner, S E Katz, P S Douglas, W J Manning
}

\begin{abstract}
Objective-To determine whether there is significant atrial or atrial appendage enlargement or functional remodelling as a result of one to two months of sustained atrial fibrillation, a duration similar to that experienced by patients undergoing warfarin anticoagulation before elective cardioversion.

Methods-To test the hypothesis that left atrial and left atrial appendage enlargement develop as a result of short term atrial fibrillation, serial anatomical and functional indices were measured using transoesophageal echocardiography (TOE) in 20 patients with recent onset atrial fibrillation (14 men, six women; mean (SEM) age 67 (2) years). Serial TOE was performed 2.5 months apart in patients with sustained atrial fibrillation.

Results-There was no significant change in left atrial area $\left(23.7 \mathrm{~cm}^{2}\right.$ to $24.1 \mathrm{~cm}^{2}$, p = 0.98); length $(5.7 \mathrm{~cm}$ to $5.7 \mathrm{~cm}$, p = 0.48); width $(5.2 \mathrm{~cm}$ to $5.2 \mathrm{~cm}$, $p=0.65)$; volume $\left(83 \mathrm{~cm}^{3}\right.$ to $87 \mathrm{~cm}^{3}$, $\mathbf{p}=0.51)$ or left atrial appendage area $(7.9$ $\mathrm{cm}^{2}$ to $\left.8.1 \mathrm{~cm}^{2}, \mathrm{p}=0.89\right)$; length $(4.6 \mathrm{~cm}$ to $4.5 \mathrm{~cm}, \mathrm{p}=0.8)$; or width $(2.5$ to $2.4 \mathrm{~cm}$, $p=0.87)$. Peak left atrial appendage velocity ejection $(0.2 \mathrm{~m} / \mathrm{s}$ to $0.2 \mathrm{~m} / \mathrm{s}$, $\mathbf{p}=0.57)$, and presence of severe spontaneous echo contrast in the left atrial appendage $(n=15(75 \%)$ to $n=13(72 \%))$ were also not significantly different. There was no correlation between changes in left atrial or left atrial appendage dimensions. Conclusions-In the setting of sustained atrial fibrillation, significant left atrial and left atrial appendage functional and anatomical remodelling do not occur with atrial fibrillation of a duration similar to that used for conservative anticoagulation in preparation for cardioversion. (Heart 1999;82:555-558)
\end{abstract}

Keywords: atrial fibrillation; left atrial appendage; remodelling

Sustained atrial fibrillation is associated with biatrial enlargement. ${ }^{1-7}$ Left atrial enlargement is a strong predictor of the recurrence of atrial fibrillation after active conversion to sinus rhythm ${ }^{8-11}$ and has been associated with an increased risk of thromboembolisation in patients with chronic atrial fibrillation. ${ }^{12}$ The duration of atrial fibrillation has also been shown to be inversely correlated with the rate of recovery of atrial mechanical duration. ${ }^{13}{ }^{14}$ Few serial data are available on the impact of shorter term sustained atrial fibrillation on left atrial appendage anatomy and function. The left atrial appendage, a cul-de-sac region of the left atrium, is of particular clinical relevance because it is the most common location for thrombus in patients with atrial fibrillation. ${ }^{15-17}$ These left atrial appendage thrombi have been closely linked to subsequent thromboembolism. ${ }^{18}$ Using serial transoesophageal echocardiography (TOE), we sought to determine if left atrial appendage enlargement or functional remodelling occur in patients with new onset atrial fibrillation with sustained atrial fibrillation for several months.

\section{Methods}

STUDY GROUP

The study population consisted of 20 patients with new onset atrial fibrillation who underwent a baseline and at least one follow up TOE with documented sustained atrial fibrillation between the initial and follow up TOE. All had a left atrial/left atrial appendage thrombus seen on initial TOE and were in sustained atrial fibrillation between studies. All subjects received chronic warfarin sodium to maintain a target international normalised ratio (INR) of 2.0 to 3.0 between echocardiographic studies.

\section{ECHOCARDIOGRAPHY}

TOE was performed using a Sonos 1000, 1500 , or 2500 instrument (Hewlett-Packard Medical Products Division, Andover, Massachusetts, USA) equipped with a $5.0 / 3.5 \mathrm{MHz}$ multiplane probe (19 patients) or $5.0 / 3.5 \mathrm{MHz}$ biplane probe (one patient), with $10 \%$ lignocaine (lidocaine) spray local anaesthesia and mild sedation with midazolam hydrochloride, meperidine, and/or fentanyl, as needed. Continuous, single lead ECG monitoring was performed during each study. Images of the left atrial and left atrial appendage were obtained in the horizontal $\left(0^{\circ}\right)$, vertical $\left(90^{\circ}\right)$, and intermediate imaging planes. The severity of left atrial spontaneous contrast was graded as 0 (none) if there was absence of dynamic "smoke-like" echoes; 1+ (minor) if there were minimal or sparsely distributed echoes; and 2+ (major) if there were intense echoes.

TOE studies were recorded on standard VHS tape and analysed using an offline workstation (Cardiology Workstation, Freeland Systems, Louisville, Colorado, USA). Left atrial length $\left(\mathrm{L}_{\mathrm{LA}}\right)$ was measured in the four chamber view (horizontal plane) and two chamber view (vertical plane) from the point of mitral leaflet coaptation to the opposite endocardial edge $\mathrm{e}^{19}$ at end diastole. Left atrial width $\left(\mathrm{W}_{\mathrm{LA}}\right)$ was measured orthogonal to the 


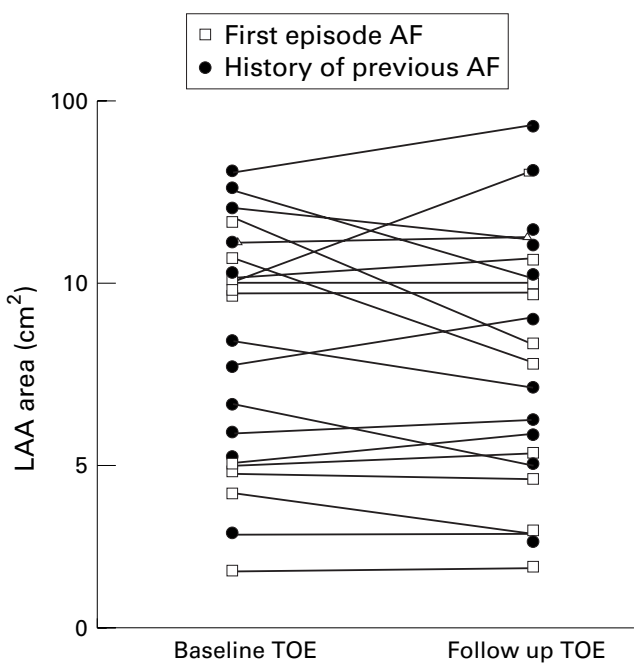

Figure 1 Individual patient left atrial appendage (LAA) area at baseline (initial transoesophageal echocardiography (TOE)) and at follow up TOE.

length between the two endocardial edges at its midpoint. ${ }^{19}{ }^{20}$ An ellipse formula was used to calculate left atrial area:

$\operatorname{Area}_{\mathrm{LA}}=(\pi / 4) \times \mathrm{L}_{\mathrm{LA}} \times \mathrm{W}_{\mathrm{LA}}$.

Left atrial volume (Volume $\mathrm{LA}_{\mathrm{LA}}$ ) was calculated using an ellipsoid model where $(\mathrm{H})$ and $(\mathrm{V})$ are measurements made in the horizontal and vertical planes, respectively:

Volume $_{\mathrm{LA}}=4 / 3 \pi(\mathrm{L} / 2) \times\left(\mathrm{W}_{(\mathrm{H})} / 2\right) \times\left(\mathrm{W}_{(\mathrm{V})} / 2\right)$.

The width of the left atrial appendage was defined in each plane by a line from the confluence of the left upper pulmonary vein and the left atrial appendage to the outermost portion of the mitral annulus. ${ }^{19} 21$ The left atrial appendage length was measured from this confluence to the appendage apex. Left atrial appendage area was measured by manual planimetry. ${ }^{1921}$ All anatomical measurements were made from cross sectional images immediately before the QRS complex.

Table 1 Serial anatomical indices of left atrium and left atrial appendage

\begin{tabular}{llll}
\hline & $\begin{array}{l}\text { Baseline } \\
\text { TOE }\end{array}$ & $\begin{array}{l}\text { Follow up } \\
\text { TOE }\end{array}$ & p Value \\
\hline Left atrium $(n=19)$ & & & \\
Length $(\mathrm{cm})(\mathrm{H})$ & $5.7(0.2)$ & $5.7(0.2)$ & 0.48 \\
Length $(\mathrm{cm})(\mathrm{V})$ & $5.9(0.1)$ & $5.9(0.2)$ & 0.81 \\
Width (cm) (H) & $5.2(0.2)$ & $5.2(0.2)$ & 0.87 \\
Width $(\mathrm{cm})(\mathrm{V})$ & $5.3(0.2)$ & $5.2(0.2)$ & 0.65 \\
Area $\left(\mathrm{cm}^{2}\right)(\mathrm{H})$ & $23.7(1.6)$ & $24.1(1.6)$ & 0.98 \\
Area $\left(\mathrm{cm}^{2}\right)(\mathrm{V})$ & $24.2(1.4)$ & $24.0(1.6)$ & 0.91 \\
Volume $\left(\mathrm{cm}^{3}\right)$ & $83.2(6.0)$ & $87.5(7.2)$ & 0.51 \\
Left atrial appendage $(n=20)$ & & \\
Length $(\mathrm{cm})(\mathrm{H})$ & $4.6(0.3)$ & $4.5(0.3)$ & 0.80 \\
Length (cm) (V) & $4.5(0.2)$ & $4.4(0.2)$ & 0.95 \\
Width $(\mathrm{cm})(\mathrm{H})$ & $2.5(0.1)$ & $2.4(0.1)$ & 0.52 \\
Width $(\mathrm{cm})(\mathrm{V})$ & $2.3(0.1)$ & $2.2(0.1)$ & 0.87 \\
Area $\left(\mathrm{cm}^{2}\right)(\mathrm{H})$ & $7.9(0.8)$ & $8.1(0.9)$ & 0.89 \\
Area $\left(\mathrm{cm}^{2}\right)(\mathrm{V})$ & $8.1(1.2)$ & $7.3(0.8)$ & 0.40 \\
Peak velocity ejection (m/s) & $0.2(0.01)$ & $0.2(0.02)$ & 0.57 \\
Severe SEC (n (\%)) & $15(75)$ & $13(72)$ & 0.29 \\
Heart rate (beats/min) & $97(5)$ & $85(4)$ & 0.10 \\
\hline
\end{tabular}

Values are mean (SEM).

$\mathrm{H}$, horizontal $\left(0^{\circ}\right)$ imaging plane; SEC, spontaneous echo contrast; TOE, transoesophageal echocardiography; V, vertical $\left(90^{\circ}\right)$ imaging plane.

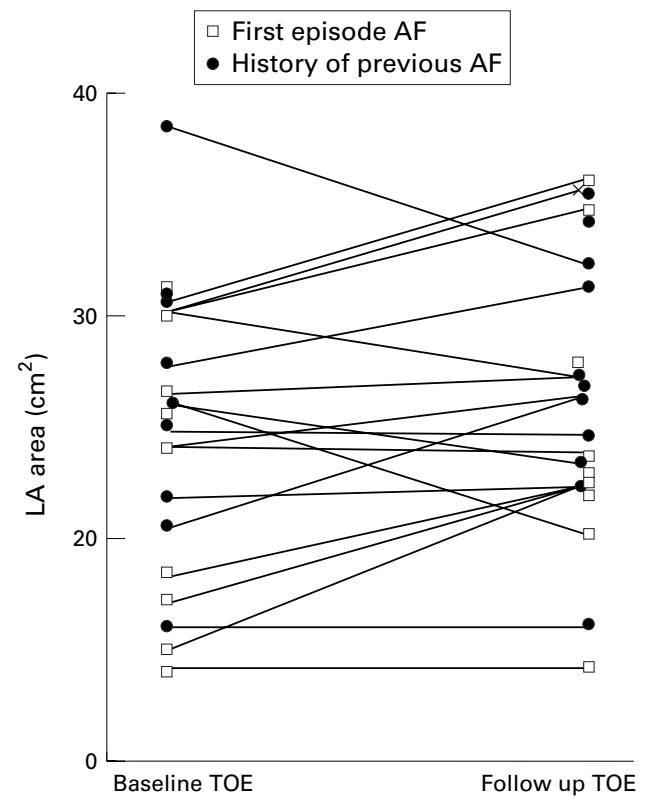

Figure 2 Individual patient left atrial (LA) area at baseline (initial transoesophageal echocardiography (TOE)) and follow up TOE.

Left atrial appendage flow velocity profiles were obtained with the pulsed Doppler sample volume placed immediately inside the appendage orifice. Maximum ejection velocities $\left(V_{\text {LAA(+)peak }}\right)$ during the $R R$ interval were measured. All analyses were performed by individuals blinded to patients' clinical data or study period.

\section{STATISTICAL ANALYSIS}

All data are expressed as mean (SEM). Mean data for at least three consecutive beats were used for individual patient data. Categorical variables were compared using the $\chi^{2}$ test with the Fisher's exact test in case of small numbers. Continuous variables were compared using analysis of variance (ANOVA, StatView, Abacus Concepts, Berkeley, California, USA). The $\chi^{2}$ test was used to compare data categorically from patients who showed an increase (versus no change or decrease) in left atrial or left atrial appendage size. All comparisons were two tailed, with significance taken as a $\mathrm{p}<0.05$.

The study was approved by the hospital committee on clinical investigation and written informed consent for TOE was obtained from all participants.

\section{Results}

BASELINE CHARACTERISTICS

The study group included 20 patients ( 14 men, six women), mean (SEM) age 67 (2) years (range 33 to 92) with clinically estimated duration of atrial fibrillation at the time of the initial TOE of $<2$ weeks in 10 patients, and at least one month in 10 patients. For nine patients, this was the first documented episode of atrial fibrillation, while 11 had a history of previous (but not sustained/chronic) atrial fibrillation. The systemic condition associated with atrial fibrillation included systemic hypertension (six patients), coronary artery disease (five patients), and rheumatic mitral disease (three 
patients). Ten patients had evidence of global left ventricular systolic dysfunction and three had focal left ventricular systolic dysfunction.

INITIAL AND FOLLOW UP ANATOMICAL AND FUNCTIONAL INDICES

Serial TOE was performed 2.5 (0.5) months apart. All patients underwent TOE without complication. Serial left atrial appendage anatomic and functional data were obtained on all 20 patients. Serial left atrial width and length measurements were interpretable in 19 patients. There were no significant differences between baseline and follow up left atrial appendage area (fig 1), length, width, volume, ejection velocity, or spontaneous echo contrast (table 1). In addition, there was no significant change in left atrial area (fig 2), length, or width (table 1). Group baseline and follow up anatomical and functional (Doppler) data are summarised in table 1 and figs 1 and 2. There was also no significant correlation between left atrial and left atrial appendage size for either initial or follow up studies. Among those in whom there was an increase in left atrial or left atrial appendage size, there was no correlation between the changes. Furthermore, there was no difference in either demographics or aetiology between the group in which left atrial or left atrial appendage size increased and the group in which they did not.

Subgroup analysis of all indices was performed for the subgroup of patients with no history of previous atrial fibrillation (nine patients). There was no significant difference for any anatomical or functional TOE indices (table 2). Subgroup analysis was also performed for patients with atrial fibrillation of brief duration (< one month, 10 patients). There were no significant differences for any anatomical or functional TOE indices (table 3).

CLINICAL FOLLOW UP

Residual left atrial appendages were seen in five subjects on follow up TOE. In four of these, the residual thrombus was smaller than the thrombus seen on the initial TOE. One subject had another TOE four months later which documented a persistent (though smaller) thrombus. Direct current (dc) cardioversion was attempted in all 15 subjects without evidence of residual thrombus on follow up TOE and

Table 2 Serial anatomical indices of left atrium and left atrial appendage for subset of patients with atrial fibrillation of less than two weeks'duration

\begin{tabular}{|c|c|c|c|}
\hline & $\begin{array}{l}\text { Baseline } \\
\text { TOE }\end{array}$ & $\begin{array}{l}\text { Follow up } \\
\text { TOE }\end{array}$ & $p$ Value \\
\hline \multicolumn{4}{|l|}{ Left atrium } \\
\hline Length $(\mathrm{cm})(\mathrm{H})$ & $5.4(0.3)$ & $5.3(0.3)$ & 0.49 \\
\hline Width $(\mathrm{cm})(\mathrm{H})$ & $4.9(0.2)$ & $5.4(0.2)$ & 0.21 \\
\hline Area $\left(\mathrm{cm}^{2}\right)(\mathrm{H})$ & $21.6(1.9)$ & $22.9(1.8)$ & 0.70 \\
\hline Volume $\left(\mathrm{cm}^{3}\right)$ & $75.6(6.4)$ & $78.3(7.2)$ & 0.86 \\
\hline \multicolumn{4}{|l|}{ Left atrial appendage } \\
\hline Length $(\mathrm{cm})(\mathrm{H})$ & $4.2(0.4)$ & $4.2(0.5)$ & 0.76 \\
\hline Width $(\mathrm{cm})(\mathrm{H})$ & $2.4(0.2)$ & $2.3(0.2)$ & 0.48 \\
\hline Area $\left(\mathrm{cm}^{2}\right)(\mathrm{H})$ & $6.8(1.1)$ & $7.0(0.9)$ & 0.76 \\
\hline Peak ejection velocity $(\mathrm{m} / \mathrm{s})$ & $0.2(0.01)$ & $0.2(0.02)$ & 0.35 \\
\hline
\end{tabular}

Values are mean (SEM).

$\mathrm{H}$, horizontal $\left(0^{\circ}\right)$ imaging plane; TOE, transoesophageal echocardiography.
Table 3 Serial anatomical indices of left atrium and left atrial appendage for the subset of patients with their first documented episode of atrial fibrillation

\begin{tabular}{|c|c|c|c|}
\hline & $\begin{array}{l}\text { Baseline } \\
\text { TOE }\end{array}$ & $\begin{array}{l}\text { Follow up } \\
\text { TOE }\end{array}$ & $p$ Value \\
\hline \multicolumn{4}{|l|}{ Left atrium } \\
\hline Length $(\mathrm{cm})(\mathrm{H})$ & $5.6(0.3)$ & $5.5(0.3)$ & 0.40 \\
\hline Width $(\mathrm{cm})(\mathrm{H})$ & $5.1(0.2)$ & $5.4(0.3)$ & 0.72 \\
\hline Area $\left(\mathrm{cm}^{2}\right)(\mathrm{H})$ & $22.9(2.0)$ & $23.6(2.7)$ & 0.76 \\
\hline Volume $\left(\mathrm{cm}^{3}\right)$ & $84.3(6.4)$ & $88.4(13)$ & 0.64 \\
\hline \multicolumn{4}{|l|}{ Left atrial appendage } \\
\hline Length $(\mathrm{cm})(\mathrm{H})$ & $4.4(0.2)$ & $4.3(0.4)$ & 0.65 \\
\hline Width $(\mathrm{cm})(\mathrm{H})$ & $2.3(0.2)$ & $2.2(0.2)$ & 0.66 \\
\hline Area $\left(\mathrm{cm}^{2}\right)(\mathrm{H})$ & $7.5(1.3)$ & $6.9(1.4)$ & 0.16 \\
\hline Peak velocity inflow $(\mathrm{m} / \mathrm{s})$ & $0.2(0.01)$ & $0.2(0.02)$ & 0.88 \\
\hline
\end{tabular}

Values are mean (SEM).

$\mathrm{H}$, horizontal $\left(0^{\circ}\right)$ imaging plane; TOE, transoesophageal echocardiography.

was successful in 13 . None experienced a clinical thromboembolic event. Cardioversion was not attempted in any patient with residual thrombus.

\section{Discussion}

Using serial transthoracic echocardiography, previous investigators have found that left atrial enlargement occurs as a result of sustained atrial fibrillation, while a decrease in left atrial size is found among those who are converted and maintained in sinus rhythm. ${ }^{1}$ Prevention of such deleterious left atrial remodelling would therefore be desirable and would be a potential benefit of early cardioversion using a TOE strategy for those in whom no thrombi are present. ${ }^{15-17}$ To our knowledge, no serial data on the impact of atrial fibrillation on left atrial appendage anatomy or functional indices have been reported.

Previous non-serial data from our laboratory had suggested intrinsic remodelling of the left atrium after one month of atrial fibrillation. ${ }^{19}$ Among patients with their first episode of atrial fibrillation, the left atrial area was found to be significantly larger in a subset of patients with atrial fibrillation of more than two weeks' duration compared with less than two weeks' duration. ${ }^{19}$ Anatomical and functional indices of the left atrial appendage were not different. These initial findings, together with those of others ${ }^{1-5}$ showing anatomical remodelling of the atria when exposed to sustained atrial fibrillation, had led to the hypothesis that sustained atrial fibrillation of a magnitude similar to the typical delay in cardioversion proscribed by conventional anticoagulation treatment before cardioversion may be sufficient to allow left atrial and left atrial appendage dilatation. Enlargement of the left atrial appendage is of clinical relevance, because it may predispose patients to thrombus formation and subsequent thromboembolism. ${ }^{18}$ Preventing such unfavourable remodelling is one of several potential benefits to the strategy of performing TOE guided early cardioversion of atrial fibrillation. Prevention of this adverse remodelling may also allow increased cardioversion success and make long term maintenance of sinus rhythm more likely.

In a series of 15 patients, Sanfilippo et al noted an increase in left atrial and right atrial size in a group of patients with sustained atrial 
fibrillation. ${ }^{1}$ Such an enlargement of the left atrium has been shown to be a powerful predictor for recurrent atrial fibrillation and is associated with an increased risk of thromboembolism among those with atrial fibrillation. ${ }^{8-12}$ In this present TOE study, we found no significant left atrial enlargement as a result of sustained atrial fibrillation of around 2.5 months. The apparent discrepancy is likely to reflect the population studied. In the study by Sanfilippo et al, patients with left atrial enlargement at baseline study were excluded, ${ }^{1}$ whereas in our study the left atria were enlarged (left atrial dimension $>4.0 \mathrm{~cm}$ ) in all patients at the time of the their initial TOE. Further, the mean interval between echocardiographic studies in the study by Sanfilippo et al was 20 months (compared with 2.5 months in our study group). We specifically chose the shorter follow up period because it has specific relevance to patients with atrial fibrillation receiving four to six weeks of warfarin treatment before electrical cardioversion.

We and others have previously shown that the recovery of atrial mechanical function is related to the duration of atrial fibrillation before cardioversion ${ }^{13}{ }^{14}$ and that left atrial size decreases after restoration of sinus rhythm. These studies suggested that atrial functional remodelling is related to the duration of atrial fibrillation before cardioversion. ${ }^{13}{ }^{14}$ We had therefore anticipated a decrease in left atrial appendage ejection velocity on the follow up TOE (compared with the initial TOE), but this hypothesis was not supported by our prospective data. Our findings suggest that Doppler indices of left atrial appendage size obtained in atrial fibrillation may not be predictive of functional variables in the left atrium and left atrial appendage after conversion to sinus rhythm.

A limitation to our study is that half of our study group had a history of previous atrial fibrillation; though analysis of patients with new onset atrial fibrillation yielded similar results, the sample was small. It is possible that left atrial and left atrial appendage enlargement had already developed in these patients, thus "masking" detection of this change. In addition, 2.5 months of sustained atrial fibrillation may not be sufficient to detect changes that may develop subsequently. However, we believe the 2.5 month data are of particular clinical relevance because they relate to a period of sustained atrial fibrillation similar to that with conventional anticoagulation before cardioversion. Finally, all of our patients had an atrial thrombus on their initial TOE and this may therefore represent a unique population for whom data are not readily applicable to the general population of patients presenting with atrial fibrillation.

In conclusion, these prospective data show that in the setting of sustained atrial fibrillation significant functional and anatomical remodel- ling of the left atrium and left atrial appendage do not occur with sustained atrial fibrillation of a duration similar to that expected with a conservative anticoagulation approach in preparation for cardioversion.

MJW is supported by the Harvard-MIT Clinical Sciences Investigator Training Program, in collaboration with Pfizer Inc,
Boston, MA, USA. WJM is supported in part by an Established Boston, MA, USA. WJM is supported in part by an Established
Investigator Grant of the American Heart Association, Dallas, Investigator Grant of the
Texas, USA $(974003 \mathrm{~N})$.

1 Sanfilippo AJ, Abascal VM, Sheehan M, et al. Atrial enlargement as a consequence of atrial fibrillation. A prospective echocardiographic study. Circulation 1990;82:792-7.

2 Petersen P, Kastrup J, Brinch K, et al. Relation between left atrial dimension and duration of atrial fibrillation. $A m \mathcal{F}$ Cardiol 1987;60:382-4.

3 Suarez GS, Lampert S, Ravid S, et al. Changes in left atrial size in patients with lone atrial fibrillation. Clin Cardiol 1991;14:652-6.

4 Probst P, Goldschlager N, Selzer A. Left atrial size and atrial fibrillation in mitral stenosis. Factors influencing their relafibrillation in mitral stenosis. Factors
tionship. Circulation 1973;48:1282-7.

5 Henry WL, Morganroth J, Pearlman AS, et al. Relation between echocardiographically determined left atrial size and atrial fibrillation. Circulation 1976;53:273-9.

6 Anderson JS, Egeblad H, Abildgaard U, et al. Atrial fibrillation and left atrial enlargement: cause or effect? F Intern Med 1991;229:253-6.

7 Keren G, Etzion T, Sherez J, et al. Atrial fibrillation and atrial enlargement in patients with mitral stenosis. $\mathrm{Am}$ Heart $\mathcal{f} 1987 ; 114: 1146-55$.

8 Verhost PM, Kamp O, Welling RC, et al. Transesophageal echocardiographic predictors for maintenance of sinus rhythm after electrical cardioversion of atrial fibrillation. Am F Cardiol 1997;79:1355-9.

9 Hoglund C, Rosenhamer G. Echocardiographic left atrial dimension as a predictor of maintaining sinus rhythm after conversion of atrial fibrillation. Acta Med Scand 1985;217: $411-15$.

10 Flaker GC, Fletcher KA, Rothbart R, et al. Clinical and echocardiographic features of intermittent atrial fibrillation echocardiographic features of intermittent atrial fibrillation that predict 355 .

11 Brodsky MA, Allen BJ, Capparelli EV, et al. Factors determining maintenance of sinus rhythm after chronic atrial fibrillation with left atrial dilation. Am $\mathcal{F}$ Cardiol 1989; 63:1065-8.

12 Stroke Prevention in Atrial Fibrillation Investigators. Predictors of thromboembolism in atrial fibrillation. II. Echocardiographic features of patients at risk. Ann Intern Med 1992;116:6-12.

13 Manning WJ, Silverman DI, Katz SE, et al. Impaired left atrial mechanical function after cardioversion: relation to the duration of atrial fibrillation. I Am Coll Cardiol 1994:23:1535-40

14 Shapiro EP, Effron MB, Lima S, et al. Transient atrial dysfunction after conversion of chronic atrial fibrillation to function after conversion of chronic atrial
sinus rhythm. Am $\mathcal{\text { Cardiol 1988; }}$ 192:1202-7.

15 Manning WJ, Silverman DI, Keighley C, et al. Transesophageal echocardiography facilitated early cardioversion from atrial fibrillation using short-term anticoagulation. Final results of a prospective 4.5 year study. $\mathcal{F}$ Am Coll Cardiol 1995;25:1354-61

16 Klein AL, Grimm RA, Black IW, et al. Cardioversion guided by transesophageal echocardiography: the ACUTE pilot study. A randomized, controlled trial. Assessment of cardioversion using transesophageal echocardiography. Ann Intern Med 1997;126:200-9.

17 Stoddard MF, Dawkins PR, Prince CR, et al. Transesophageal echocardiography guidance of cardioversion in patients with atrial fibrillation. Am Heart f 1995;129:120415.

18 Chan KL, and SPAF Investigators. A prospective study to assess transesophageal echocardiographic (TEE) findings in the prediction of stroke in high risk patients with atrial in the prediction of stroke in high risk patients
fibrillation [abstract]. Circulation 1996;94:I-216.

19 Rubin DN, Katz SE, Riley MF, et al. Evaluation of left atrial appendage anatomy and function in recent onset atrial fibrillation by transesophagel echocardiography. Am $7 \mathrm{Car}$ diol 1996:78:774-8.

20 Drexler M, Erbel R, Muller U, et al. Measurement of intracardiac dimensions and structures in normal young adult subjects by transesophageal echocardiography. $A m$ f Cardiol 1990;65:1491-6.

21 Chan SK, Kannam JP, Douglas PS, et al. Multiplane transesophageal echocardiographic assessment of the left atrial appendage anatomy and function. Am $\mathcal{F}$ Cardiol 1995;76: $528-30$. 